\title{
Relationship between retinal blood flow and cytokines in central retinal vein occlusion
}

\author{
Hidetaka Noma ${ }^{1 *}$, Kanako Yasuda', Tatsuya Mimura², Akemi Ofusa ${ }^{1}$ and Masahiko Shimura ${ }^{1}$
}

\begin{abstract}
Background: We evaluated the relationship between retinal blood flow and aqueous humor levels of cytokines/ growth factors in patients with central retinal vein occlusion (CRVO).

Methods: In an observational study, 64 eyes of 64 CRVO patients were examined before anti-vascular endothelial growth factor (VEGF) therapy. Blood flow was assessed in large vessels around and the optic disk by determining the mean blur rate using laser speckle flowgraphy. Aqueous humor samples were obtained from the patients during anti-VEGF therapy and levels of the following molecules were measured by the suspension array method: soluble VEGF receptor (sVEGFR)-1, sVEGFR-2, VEGF, plancental growth factor (PIGF), platelet-derived growth factor (PDGF)-AA, soluble intercellular adhesion molecule (sICAM)-1, monocyte chemotactic protein (MCP)-1, interleukin (IL)-6, IL-8, IL-12(p70), and IL-13.
\end{abstract}

Results: The mean blur rate of the affected eye was significantly lower than that of the unaffected eye. The mean blur rate showed a significant negative correlation with the log-transformed aqueous humor levels of PIGF, sICAM1 , and IL-8, but not VEGF.

Conclusions: These findings suggest that retinal blood flow velocity might be more strongly correlated with inflammatory factors than VEGF in patients with nonischemic CRVO and macular edema.

Keywords: Central retinal vein occlusion, Laser speckle flowgraphy, Retinal blood flow, Placental growth factor, Soluble intercellular adhesion molecule-1, Interleukin-8

\section{Background}

Central retinal vein occlusion (CRVO) is a common condition that often causes macular edema, which is the most frequent reason for visual impairment in these patients. In CRVO, compression of the central retinal vein by an arteriosclerotic central retinal artery in the vicinity of the lamina cribrosa leads to venous thrombosis [1]. Thus, understanding the abnormalities of retinal hemodynamics underlying the pathogenesis of CRVO

\footnotetext{
*Correspondence: noma-hide@umin.ac.jp

'Department of Ophthalmology, Hachioji Medical Center, Tokyo Medical University, 1163, Tatemachi, Hachioji, Tokyo 193-0998, Japan

Full list of author information is available at the end of the article
}

is critically important. Recently, it was reported that increased production of vascular endothelial growth factor (VEGF) is associated with macular edema in CRVO patients [2]. In addition, treatment with ranibizumab or aflibercept achieves significant improvement of visual acuity in CRVO patients with macular edema, supporting a role of VEGF in this condition [3, 4].

Measurement of ocular blood flow is commonly performed in various ophthalmic diseases, with both invasive and noninvasive methods being used to obtain blood flow data. We previously investigated the relationship between the blood flow velocity in the perifoveal capillaries and macular edema in patients with retinal vein occlusion by

C C The Author(s). 2020 Open Access This article is licensed under a Creative Commons Attribution 4.0 International License, which permits use, sharing, adaptation, distribution and reproduction in any medium or format, as long as you give appropriate credit to the original author(s) and the source, provide a link to the Creative Commons licence, and indicate if changes were made. The images or other third party material in this article are included in the article's Creative Commons licence, unless indicated otherwise in a credit line to the material. If material is not included in the article's Creative Commons licence and your intended use is not permitted by statutory regulation or exceeds the permitted use, you will need to obtain permission directly from the copyright holder. To view a copy of this licence, visit http://creativecommons.org/licenses/by/4.0/ The Creative Commons Public Domain Dedication waiver (http://creativecommons.org/publicdomain/zero/1.0/) applies to the data made available in this article, unless otherwise stated in a credit line to the data. 
the tracing method using fluorescein angiography and a scanning laser ophthalmoscope $[5,6]$, but this method is invasive. On the other hand, several noninvasive techniques are available, including color Doppler imaging [7], laser Doppler velocimetry [8], and laser speckle flowgraphy (LSFG) [9-12]. Among these methods, LSFG is convenient for measuring blood flow in the clinical setting. Yamada et al. recently reported that the aqueous humor level of VEGF was correlated with the mean blur rate (MBR) in CRVO patients [13]. In addition to VEGF, we have found that intraocular levels of several inflammatory factors are significantly correlated with the severity of macular edema in CRVO patients [14]. However, the relation between intraocular levels of various factors/cytokines and MBR has not been clarified. Accordingly, we investigated the relation of MBR to aqueous humor levels of 11 cytokines or growth factors in patients with nonischemic CRVO receiving anti-VEGF therapy for macular edema.

\section{Methods \\ Subjects}

Our current research followed the tenets of the Declaration of Helsinki, with approval for this study obtained from the Ethics Committee of Tokyo Medical University Hachioji Medical Center. This manuscript does not include any individual participant details. This prospective observational study was conducted on 64 eyes of 64 patients with CRVO (30 females and 34 males) with no history of treatment. Each patient received intravitreal ranibizumab injection (IRI) at a dose of $0.5 \mathrm{mg}$ in 0.05 ml (Lucentis; Genentech, Inc., South San Francisco, CA) or intravitreal aflibercept injection (IAI) at a dose of 2 $\mathrm{mg}$ in $0.05 \mathrm{ml}$ (Eylea; Regeneron Pharmaceuticals, Inc., Tarrytown, NY, and Bayer HealthCare Pharmaceuticals, Berlin, Germany). The criteria for IRI or IAI therapy were a central macular thickness $(\mathrm{CMT})>300 \mu \mathrm{m}$ and best-corrected visual acuity $(\mathrm{BCVA})<25 / 30$. None of the patients had received treatment for macular edema before this study. The systolic blood pressure (SBP) and diastolic blood pressure (DBP) were measured with a mercury sphygmomanometer. Hypertension was diagnosed if patients were receiving antihypertensive drugs or had a blood pressure $\geq 140 / 90 \mathrm{mmHg}$.

After each patient gave informed consent, blood flow was measured in the large vessels at the optic disk and aqueous levels of cytokines were determined. LSFG was used to evaluate blood flow as the MBR $[11,13]$, while a mean volume of $0.1 \mathrm{~mL}$ of aqueous humor was collected by anterior chamber limbal paracentesis with a 30 -gauge needle attached to an insulin syringe. IRI or IAI therapy was then administered through the pars plana at $3.5 \mathrm{~mm}$ from the limbus. The aqueous humor levels of cytokines were measured with enzyme-linked immunosorbent assays (Cat. No. HSCRMAG-32 K-02: sVEGFR1 and
sVEGFR2; Cat. No. HCYTOMAG-60 K-08: VEGF, PDGF-AA, MCP-1, IL-6, IL-8, IL-12(p70) and IL-13; Cat. No. HCVD1MAG-67 K-01: PlGF; Cat. No. HCVD2MAG-67 K-01: sICAM-1) according to the manufacturer's instructions (Funakoshi Corporation Ltd., Tokyo, Japan) [14]. We obtained informed consent for aqueous humor puncture from patients, as well as IRB approval. BCVA was determined as the logarithm of the minimum angle of resolution (LogMAR). Exclusion criteria were a history of glaucoma, uveitis, retinal diseases other than CRVO, diabetes mellitus, rubeosis iridis, ocular infection, laser photocoagulation, intraocular surgery (including cataract surgery), and conditions causing difficulty with measurement of MBR (cataract with severe opacity, vitreous hemorrhage, inadequate mydriasis, or corneal opacity). Ischemic CRVO was defined as more than 10 disc areas of nonperfusion on fluorescein angiography according to the Central Retinal Vein Occlusion Study Group [15], and patients with ischemic CRVO were also excluded.

\section{Laser speckle flowgraphy}

The LSFG system used in this study (LSFG-NAVI; Softcare Co, Ltd., Fukuoka, Japan) has been described previously $[11,13]$. In brief, light reflected from the fundus produces a speckled pattern in the plane where the area sensor is focused, while light reflected by moving erythrocytes causes blurring of the speckle pattern [16]. A fundus camera equipped with an $830 \mathrm{~nm}$ diode laser and a charge-coupled device sensor $(750 \times 360$ pixels $)$ were used to obtain images of the speckle contrast pattern produced by interference as laser light was scattered by red blood cells moving through vessels in the ocular fundus. Images were acquired continuously at 30 frames/sec over a 4-s period and then averaged to produce a composite map of ocular blood flow.

The MBR thus determined was expressed in arbitrary units (AU) and displayed as a 2-dimensional color-coded map of blood flow velocity. After manually setting a circle around the optic disc by using a rubber band to delineate the disc rim, we investigated the MBR of the major vessels (arteries and veins) within this region (Fig. 1). We evaluated the microcirculation in the head of the optic nerve by measuring the MBR of the optic disc, as reported previously [17]. We fitted an elliptical band around the optic disc (Fig. 1), so measurements of MBR within the region were not affected by the vessel tortuousness. Therefore, we were able to measure the MBR in all cases. Since the MBR in the vascular area includes choroidal blood flow, we subtracted the mean MBR of the tissue area from the mean MBR of the vascular area [18] to evaluate blood flow in the retinal vessels without the influence of choroidal flow. All measurements were performed in triplicate and the mean 
A
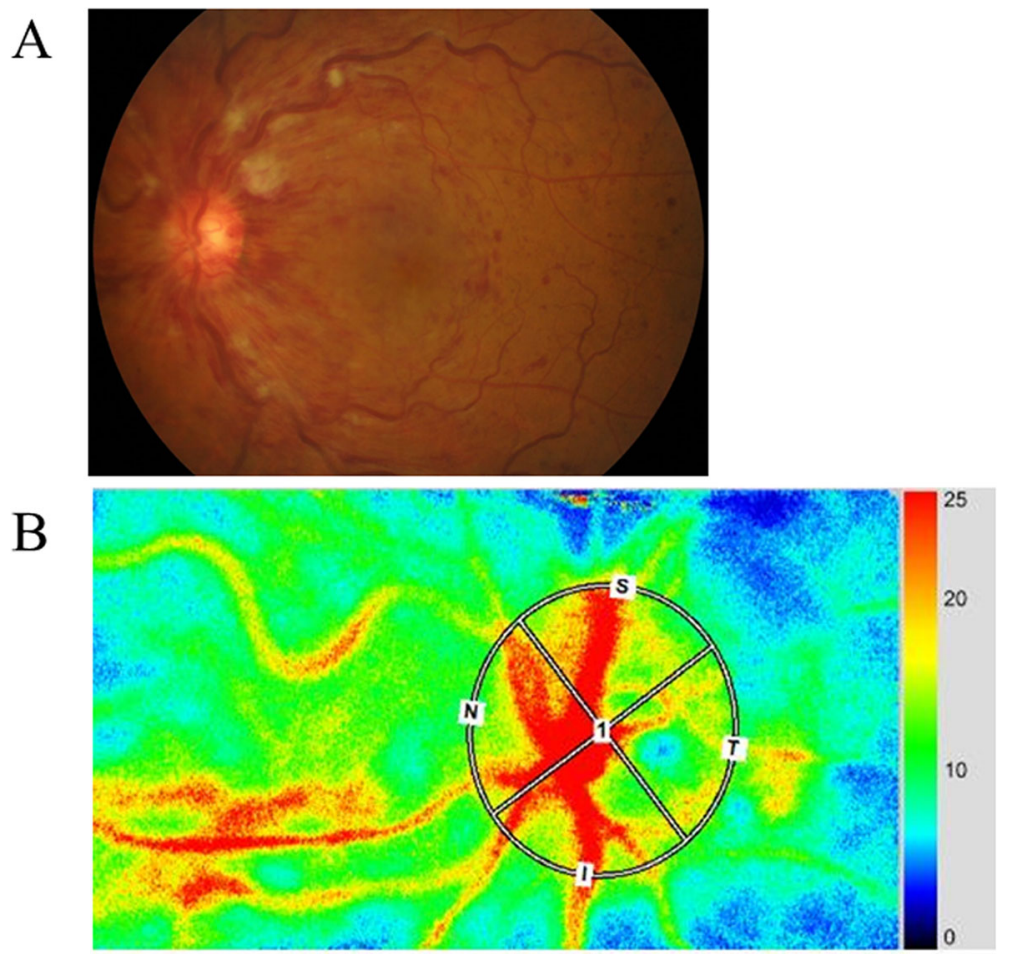

Fig. 1 Representative fundus color photograph and representative MBR data obtained with LSFG. a Fundus color photograph shows central retinal vein occlusion. b A circle was manually using an elliptical rubber band to delineate the disc rim. Red and blue indicate faster and slower blood flow, respectively

MBR value was calculated. Eye positions were recorded by performing LSFG with an auto tracking function, making it possible to capture the same area again during subsequent examinations with high reproducibility. There were no comorbidities in the unaffected eyes.

\section{Statistical analysis}

All results are expressed as the mean \pm standard deviation, as the median with interquartile range, or as frequencies. Paired $t$-test was employed to compare normally distributed continuous variables. To investigate the relations among cytokines, inflammatory factors, SBP, DBP, and MBR, Spearman's rankorder correlation coefficients or Pearson's correlation coefficients were calculated. Normality of data was assessed using the Shapiro-Wilk test. Statistical significance was considered at $P<0.05$.

\section{Results}

The clinical characteristics of the 64 CRVO patients with macular edema are summarized in Table 1. They included 30 women and 34 men aged $69.2 \pm 10.6$ years (mean $\pm \mathrm{SD}$ ). The mean duration of macular edema was $35.6 \pm 27.3$ days (range: $10-120$ days). The duration of macular edema was defined as the estimated loss of visual acuity due to intravitreal treatment. Fifty patients
(78.1\%) had hypertension and 27 patients (42.2\%) had hyperlipidemia. At the initial examination, mean BCVA was logMAR $0.57 \pm 0.37$ and mean CMT was $716 \pm$ $192 \mu \mathrm{m}$. MBR was significantly lower in the affected eye than in the unaffected eye $(21.7 \pm 8.1 \mathrm{AU}$ vs. $30.4 \pm 8.7$ AU, $P<0.001$ ) (Fig. 2) (paired $t$-test). There was no significant difference between MBR at baseline $(21.7 \pm 8.1$ AU) and 1 month after intravitreal treatment $(22.0 \pm 9.2$ AU) $(P=0.775)$ (paired $t$-test). There was no correlation

Table 1 Clinical and demographic data of the CRVO patients

\begin{tabular}{ll}
\hline & CRVO \\
\hline No. (Female/Male) & $64(30 / 34)$ \\
Age, years (mean \pm SD) & $69.2 \pm 10.6$ \\
Hypertension $(n)$ & $50(78.1 \%)$ \\
$\quad$ Systolic blood pressure $(\mathrm{mmHg})$ & $144 \pm 14$ \\
$\quad$ Diastolic blood pressure $(\mathrm{mmHg})$ & $70 \pm 12$ \\
Hyperlipidemia $(n)$ & $27(42.2 \%)$ \\
Duration of CRVO, days (mean \pm SD) & $35.6 \pm 27.3$ \\
BCVA, logMAR (mean \pm SD) & $0.57 \pm 0.37$ \\
Foveal thickness, $\mu m$ (mean \pm SD) & $716 \pm 192$ \\
Vessels for MBR measurement (number/eye) & $5.0 \pm 1.4$ \\
\hline
\end{tabular}

CRVO Central retinal vein occlusion, SD Standard deviation, No. Number of eyes, BCVA Best-corrected visual acuity, logMAR Logarithm of minimal angle of resolution; $M B R$, mean blur rate 


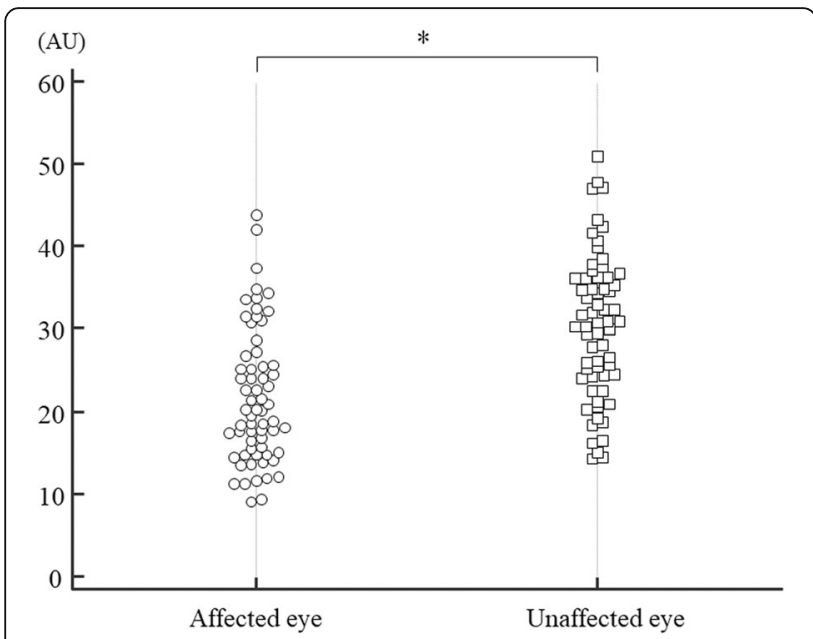

Fig. 2 Mean blur rate of the affected and unaffected eyes. The mean blur rate was significantly lower in the affected eye than the unaffected eye $(21.7 \pm 8.1 \mathrm{AU}$ vs. $30.4 \pm 8.7 \mathrm{AU}, P<0.001)$

between MBR and SBP or DBP $(r=0.17, P=0.186$ and $\mathrm{r}=-0.01, P=0.991$, respectively) (Pearson's correlation coefficient). However, significant correlations were noted between MBR and BCVA, and between MBR and CMT $(\mathrm{r}=-0.37, P=0.003$ and $\mathrm{r}=-0.27, P=0.030$, respectively) (Pearson's correlation coefficient).There were also no correlations between the mean duration of macular edema and the aqueous humor levels of sVEGFR-1, sVEGFR-2, VEGF, PIGF, PDGF-AA, sICAM-1, MCP-1, IL-6, IL-8, IL-12 (p70), or IL-13 $(\mathrm{r}=0.01, P=0.919, \mathrm{r}=$ - 0.09, $P=0.456, \mathrm{r}=-0.03, P=0.821, \mathrm{r}=-0.24, P=$ $0.054, \mathrm{r}=-0.10, P=0.433, \mathrm{r}=-0.14, P=0.243, \mathrm{r}=-$ $0.18, P=0.141, \mathrm{r}=0.06, P=0.593, \mathrm{r}=-0.11, P=0.351$, $\mathrm{r}=-0.08, P=0.508$, and $\mathrm{r}=0.01, P=0.984$, respectively) (Spearman's rank-order correlation coefficient or Pearson's correlation coefficient).

Baseline aqueous humor levels of the 11 molecules tested (growth factors, cytokines, and receptors), including sVEGFR-1, sVEGFR-2, VEGF, PlGF, PDGF-AA, sICAM-1, MCP-1, IL-6, IL-8, IL-12 (p70), and IL-13, are listed in Table 2. MBR showed a significant negative correlation with the log-transformed levels of PIGF, sICAM-1, and IL-8 $(\mathrm{r}=-0.27, P=0.031, \mathrm{r}=-0.31, P=$ 0.019, and $\mathrm{r}=-0.27, P=0.033$, respectively) (Fig. 3) (Pearson's correlation coefficient). On the other hand, MBR was not significantly correlated with the logtransformed levels of sVEGFR-1, sVEGFR-2, VEGF, PDGF-AA, MCP-1, IL-6, IL-12 (p70), or IL-13 (Fig. 3) (Pearson's correlation coefficient).

\section{Discussion}

There were two main findings of this study performed in patients with nonischemic CRVO and macular edema. (1) The MBR of the affected eye was
Table 2 Aqueous Humor Factors/Cytokines at Baseline

\begin{tabular}{ll}
\hline Factors/Cytokines & Baseline \\
\hline sVEGFR-1 $(\mathrm{pg} / \mathrm{ml})$ & $1129[391-2082]$ \\
sVEGFR-2 $(\mathrm{pg} / \mathrm{ml})$ & $520[360-728]$ \\
VEGF $(\mathrm{pg} / \mathrm{ml})$ & $77.0[28.7-129]$ \\
PIGF $(\mathrm{pg} / \mathrm{ml})$ & $6.82[2.66-13.4]$ \\
MCP-1 $(\mathrm{pg} / \mathrm{ml})$ & $2169[1335-2900]$ \\
sICAM-1 $(\mathrm{pg} / \mathrm{ml})$ & $10,100[3180-28,100]$ \\
PDGF-AA $(\mathrm{pg} / \mathrm{ml})$ & $21.8[14.9-33.3]$ \\
IL-6 $(\mathrm{pg} / \mathrm{ml})$ & $12.3[6.39-27.6]$ \\
IL-8 $(\mathrm{pg} / \mathrm{ml})$ & $32.8[15.1-54.5]$ \\
IL-12 $(\mathrm{pg} / \mathrm{ml})$ & $1.62[0.27-2.90]$ \\
IL-13 $(\mathrm{pg} / \mathrm{ml})$ & $0.50[0.12-3.60]$ \\
\hline
\end{tabular}

SVEGFR Soluble vascular endothelial growth factor receptor, VEGF Vascular endothelial growth factor, PIGF Placental growth factor, MCP Monocyte chemotactic protein, sICAM Soluble intercellular adhesion molecule, PDGF Platelet-derived growth factor, IL Interleukin

significantly lower than the MBR of the unaffected eye. (2) MBR showed a significant negative correlation with the log-transformed aqueous humor levels of PIGF, sICAM-1, and IL-8. These findings suggest that retinal blood flow velocity might be more strongly correlated with levels of inflammatory factors than VEGF in patients with nonischemic CRVO and macular edema.

This study demonstrated that the MBR of the affected eye was significantly lower than that of the unaffected eye, although we excluded patients with ischemic CRVO because they can potentially develop neovascular glaucoma and require pan-retinal photocoagulation. A number of previous studies have also demonstrated that blood flow velocity is lower in eyes with CRVO than in normal eyes [13, 19-21], corresponding to our finding.

In addition, we identified a significant correlation between the decrease of MBR and a higher aqueous humor level of sICAM-1, suggesting that sICAM-1 influences the blood flow velocity in patients with nonischemic CRVO and macular edema. Expression of ICAM-1 has been demonstrated in the retinal vascular endothelium, retinal pigment epithelium, and choroid by in vivo and in vitro studies, and ICAM-1 is also expressed by leukocytes migrating into the retina [22]. It was reported that upregulation of ICAM-1 expression induces retinal leukostasis, with increased rolling and adhesion of leukocytes to vessel walls that leads to stagnation [23]. It was also reported that retinal vein occlusion in vivo increases leukocyte rolling and adhesion to the vein walls, resulting in stagnant blood flow [24]. Thus, entrapment of leukocytes associated with increased rolling and adhesion of these cells may reduce the MBR in patients with nonischemic CRVO and macular edema. 


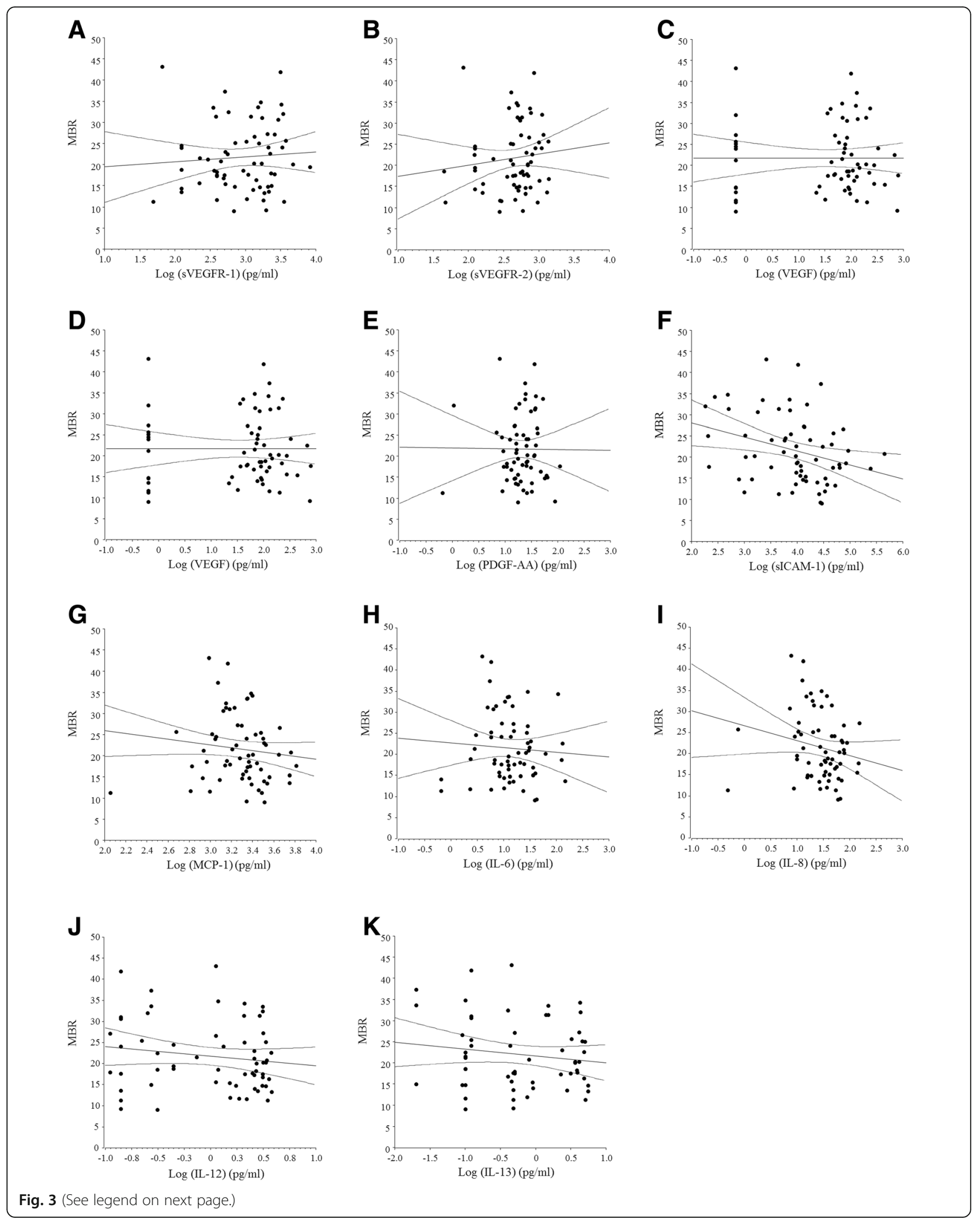




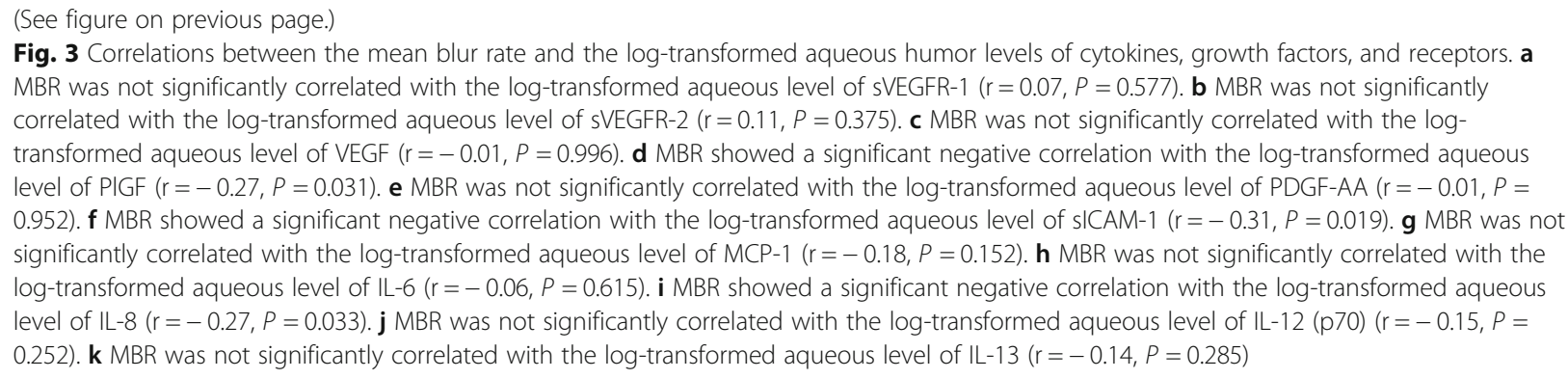

This study also demonstrated a significant negative correlation between MBR and the aqueous humor levels of PIGF and IL-8. PIGF is a member of the VEGF family $[25,26]$, and it promotes the proliferation of endothelial cells [27] and enhances leukocyte chemotaxis [27, 28]. PIGF binds exclusively to VEGFR-1 [29] and shows higher affinity for this receptor than VEGF [30]. On the other hand, IL-8 is a potent chemoattractant that activates neutrophils and T cells. Production of IL-8 is induced by exposure of vascular endothelial cells to hypoxia and oxidative stress [31-33], and it was reported that IL-8 promotes the adhesion of leukocytes to the vascular endothelium [34, 35]. Thus, PIGF and IL-8 could promote chemotaxis and adhesion of leukocytes that reduces the MBR in CRVO patients with macular edema. We previously reported that the aqueous humor levels of PIGF, sICAM-1, and IL-8 were significantly correlated with each other in CRVO patients [14]. In addition, the mean duration of macular edema was unrelated to the levels of 3 cytokines negatively correlated with the MBR. This suggests that the negative correlations of these cytokines were probably not just due to the duration of symptoms, making it possible that the three factors act together to reduce MBR in patients with nonischemic CRVO and macular edema.

Unexpectedly, we could not identify a significant correlation between MBR and the log-transformed aqueous humor level of VEGF, although Yamada et al. [13] previously reported such a correlation. These differing results were probably obtained because we excluded patients with ischemic CRVO. Since VEGF levels are very high in ischemic CRVO, it may be easier to demonstrate a relation with MBR. Williamson and Baxter [36] reported that a minimum blood velocity $<3.0 \mathrm{~cm} / \mathrm{sec}$ was highly predictive of the development of iris neovascularization in patients with CRVO. Taken together with these reports, our findings suggest that MBR might be more strongly influenced by inflammatory factors than VEGF in patients with nonischemic CRVO and macular edema. However, Yamada and colleagues reported a strong correlation of flow parameters (MBR and arteriovenous passage time) with VEGF levels and a lower affected/ healthy eye MBR ratio in ischemic CRVO [13]. Thus,
MBR and various cytokines may be correlated along with higher VEGF levels in ischemic patients. Based on the present findings, it is possible that elevation of the intravascular pressure due to malperfusion drives cystoid macular edema, while consequent leakage of blood compounds into the ocular tissues induces an inflammatory response with elevation of various cytokines that exacerbates this condition. Therefore, further data are required to more fully reveal the relationship between MBR and cytokines.

We previously reported that there are significant differences in the vitreous fluid levels of VEGF, sICAM-1, and IL- 6 between nonischemic and ischemic cases of CRVO, as well as a significant correlation between the flare value (as an index of inflammation) and vitreous levels of VEGF, sICAM-1, and IL-6 in patients with CRVO [37]. Those previous findings suggested that ischemia and inflammation are both related to the pathogenesis of ischemic CRVO, while inflammation is related more to the pathogenesis of nonischemic CRVO. Furthermore, the flare value correlated more closely with the vitreous level of VEGF than with inflammatory factors in patients with CRVO [37], so anti-VEGF therapy seems to be more effective than anti-inflammatory agents not only in ischemic CRVO but also in nonischemic CRVO. However, inflammation is more closely related to the pathogenesis of nonischemic CRVO, so anti-inflammatory agents are also considered effective in nonischemic CRVO. The efficacy of anti-inflammatory agents in nonischemic CRVO also warrants clinical investigation.

The present study had the following limitations. While we found no significant correlation between MBR and VEGF, this might have been due to marked variation of VEGF values among patients or unknown confounders. Unfortunately, it is difficult to obtain data on aqueous humor cytokine levels at multiple time points because sampling cannot be done ethically in patients without recurrence of macular edema. Further attempts will be required to measure aqueous humor cytokine levels over time in future studies. Furthermore, this study was a cross-sectional study with a focus on the relationship between retinal blood flow and cytokine levels. 
Therefore, we did not investigate the relationship between MBR and reaction to anti-VEGF therapy in this study; this relationship will need to be confirmed in future studies. In addition, the clinical pictures of nonischemic and ischemic CRVO are generally quite different [38], which is why we excluded patients with ischemic CRVO from this study. As a result, patients with neovascular glaucoma, panretinal photocoagulation, and severe loss of visual acuity were also excluded. Further studies are be required to compare the retinal blood flow and levels of cytokines between nonischemic and ischemic CRVO.

\section{Conclusions}

MBR was significantly lower in the affected eye than the unaffected eye in patients who had nonischemic CRVO and macular edema. MBR showed a significant negative correlation with the log-transformed aqueous humor levels of PIGF, sICAM-1, and IL-8, but not VEGF. Our findings suggest that MBR might be better correlated with inflammatory factors such as sICAM-1 than VEGF in patients who have nonischemic CRVO and macular edema.

\begin{abstract}
Abbreviations
AU: Arbitrary units; BCVA: Best-corrected visual acuity; CMT: Central macular thickness; CRVO: Central retinal vein occlusion; DBP: Diastolic blood pressure; IAI: Intravitreal aflibercept injection; IL: Interleukin; IRI: Intravitreal ranibizumab injection; LSFG: Laser speckle flowgraphy; MBR: Mean blur rate;

MCP: Monocyte chemotactic protein; PDGF: Platelet-derived growth factor; PIGF: Plancental growth factor; sICAM: Soluble intercellular adhesion molecule; SBP: Systolic blood pressure; sVEGFR: Soluble vascular endothelial growth factor receptor; VEGF: Vascular endothelial growth factor
\end{abstract}

\section{Acknowledgements}

We thank Katsunori Shimada (Department of Biostatistics, STATZ Corporation, Tokyo) for assistance with the statistical analysis.

\section{Ethics approval and consent to participation}

This study was conducted at the Department of Ophthalmology of Tokyo Medical University (Tokyo, Japan) and approval was obtained from the University Ethics Committee. The study procedures conformed to the principles of the Declaration of Helsinki and all patients gave written informed consent before being enrolled. This study was registered in the University Hospital Medical Information Network (UMIN) clinical trials registry. The registration number is UMIN000029067.

\section{Authors' contributions}

$\mathrm{HN}$ and MS were involved in the design and conduct of the study. Collection and management of the data were done by HN, KY, AO and MS, while analysis and interpretation of the data were performed by H.N., T.M., and M.S. The first draft of the manuscript was prepared by HN, while review and approval of the manuscript was performed by M.S. The authors read and approved the final version of the manuscript.

\section{Funding}

No funding was received for this research.

\section{Availability of data and materials}

Data will not be shared because the authors are performing other analyses that have not yet been published.

\section{Consent for publication}

Written informed consent for publication of clinical images was obtained from the individual patients. The details of consent to publication were included in the consent form for participation in this study.

\section{Competing interests}

The authors declare that they have no competing interests.

\section{Author details}

${ }^{1}$ Department of Ophthalmology, Hachioji Medical Center, Tokyo Medical University, 1163, Tatemachi, Hachioji, Tokyo 193-0998, Japan. ²Department of Ophthalmology, Teikyo University School of Medicine, Tokyo, Japan.

Received: 2 July 2019 Accepted: 27 May 2020

Published online: 05 June 2020

\section{References}

1. Hayreh SS. So-called "central retinal vein occlusion". I. Pathogenesis, terminology, clinical features. Ophthalmologica. 1976;172:1-13.

2. Noma H, Funatsu H, Mimura T, Harino S, Hori S. Vitreous levels of interleukin-6 and vascular endothelial growth factor in macular edema with central retinal vein occlusion. Ophthalmology. 2009;116:87-93.

3. Campochiaro PA, Brown DM, Awh CC, Lee SY, Gray S, Saroj N, et al. Sustained benefits from ranibizumab for macular edema following central retinal vein occlusion: twelve-month outcomes of a phase III study. Ophthalmology. 2011;118:2041-9.

4. Brown DM, Heier JS, Clark WL, Boyer DS, Vitti R, Berliner AJ, et al. Intravitreal aflibercept injection for macular edema secondary to central retinal vein occlusion: 1-year results from the phase 3 COPERNICUS study. Am J Ophthalmol. 2013;155:429-7 e427.

5. Noma H, Funatsu H, Sakata K, Harino S, Nagaoka T, Mimura T, et al. Macular microcirculation and macular oedema in branch retinal vein occlusion. $\mathrm{Br}$ J Ophthalmol. 2009;93:630-3.

6. Noma H, Funatsu H, Mimura T, Shimada K. Perifoveal microcirculation in macular oedema with retinal vein occlusion. Open Ophthalmol J. 2012;6:63-4.

7. Lieb WE, Cohen SM, Merton DA, Shields JA, Mitchell DG, Goldberg BB. Color Doppler imaging of the eye and orbit. Technique and normal vascular anatomy. Arch Ophthalmol. 1991;109:527-31.

8. Yoshida A, Feke GT, Green GJ, Goger DG, Matsuhashi M, Jalkh AE, et al. Retinal circulatory changes after scleral buckling procedures. Am J Ophthalmol. 1983;95:182-8.

9. Tamaki Y, Araie M, Hasegawa T, Nagahara M. Optic nerve head circulation after intraocular pressure reduction achieved by trabeculectomy. Ophthalmology. 2001;108:627-32.

10. Yaoeda K, Shirakashi M, Funaki S, Funaki H, Nakatsue T, Abe H. Measurement of microcirculation in the optic nerve head by laser speckle flowgraphy and scanning laser Doppler flowmetry. Am J Ophthalmol. 2000; 129:734-9.

11. Sugiyama T, Araie M, Riva CE, Schmetterer L, Orgul S. Use of laser speckle flowgraphy in ocular blood flow research. Acta Ophthalmol. 2010;88:723-9.

12. Wang L, Cull GA, Piper C, Burgoyne CF, Fortune B. Anterior and posterior optic nerve head blood flow in nonhuman primate experimental glaucoma model measured by laser speckle imaging technique and microsphere method. Invest Ophthalmol Vis Sci. 2012;53:8303-9.

13. Yamada Y, Suzuma K, Matsumoto M, Tsuiki E, Fujikawa A, Harada T, et al. Retinal blood flow correlates to aqueous vascular endothelial growth factor in central retinal vein occlusion. Retina. 2015;35:2037-42.

14. Noma H, Mimura T, Yasuda K, Shimura M. Role of soluble vascular endothelial growth factor receptor signaling and other factors or cytokines in central retinal vein occlusion with macular edema. Invest Ophthalmol Vis Sci. 2015;56:1122-8

15. Baseline and early natural history report: the Central Vein Occlusion Study. Arch Ophthalmol. 1993:111:1087-95.

16. Isono H, Kishi S, Kimura Y, Hagiwara N, Konishi N, Fujii H. Observation of choroidal circulation using index of erythrocytic velocity. Arch Ophthalmol. 2003;121:225-31.

17. Ubuka M, Sugiyama T, Onoda Y, Shiba T, Hori Y, Maeno T. Changes in the blood flow of the optic nerve head induced by different concentrations of epinephrine in intravitreal infusion during vitreous surgery. Invest Ophthalmol Vis Sci. 2014;55:1625-9. 
18. Matsumoto M, Suzuma K, Yamada Y, Tsuiki E, Fujikawa A, Kitaoka T. Retinal blood flow after INTRAVITREAL BEVACIZUMAB is a predictive factor for outcomes of macular edema associated with central retinal vein occlusion. Retina. 2018:38:283-91.

19. Michelson G, Harazny J. Increased vascular resistance for venous outflow in central retinal vein occlusion. Ophthalmology. 1997;104:659-63.

20. Horio N, Horiguchi M. Retinal blood flow and macular edema after radial optic neurotomy for central retinal vein occlusion. Am J Ophthalmol. 2006; 141:31-4.

21. Crama N, Gualino V, Restori M, Charteris DG. Central retinal vessel blood flow after surgical treatment for central retinal vein occlusion. Retina. 2010; 30:1692-7.

22. Elner SG, Elner VM, Pavilack MA, Todd RF 3rd, Mayo-Bond L, Franklin WA, et al. Modulation and function of intercellular adhesion molecule-1 (CD54) on human retinal pigment epithelial cells. Lab Invest. 1992;66:200-11.

23. Miyamoto K, Khosrof S, Bursell SE, Rohan R, Murata T, Clermont AC, et al. Prevention of leukostasis and vascular leakage in streptozotocin-induced diabetic retinopathy via intercellular adhesion molecule-1 inhibition. Proc Natl Acad Sci U S A. 1999;96:10836-41.

24. Tsujikawa A, Ogura Y, Hiroshiba N, Miyamoto K, Kiryu J, Honda Y. In vivo evaluation of leukocyte dynamics in retinal ischemia reperfusion injury. Invest Ophthalmol Vis Sci. 1998;39:793-800.

25. Maglione D, Guerriero V, Viglietto G, Delli-Bovi P, Persico MG. Isolation of a human placenta cDNA coding for a protein related to the vascular permeability factor. Proc Natl Acad Sci U S A. 1991;88:9267-71.

26. De Falco S, Gigante B, Persico MG. Structure and function of placental growth factor. Trends Cardiovasc Med. 2002;12:241-6.

27. Carmeliet P. Mechanisms of angiogenesis and arteriogenesis. Nat Med. 2000:6:389-95.

28. Clauss M, Weich $H$, Breier G, Knies U, Rockl W, Waltenberger J, et al. The vascular endothelial growth factor receptor Flt-1 mediates biological activities. Implications for a functional role of placenta growth factor in monocyte activation and chemotaxis. J Biol Chem. 1996;271:17629-34.

29. Park JE, Chen HH, Winer J, Houck KA, Ferrara N. Placenta growth factor. Potentiation of vascular endothelial growth factor bioactivity, in vitro and in vivo, and high affinity binding to Flt-1 but not to Flk-1/KDR. J Biol Chem. 1994;269:25646-54.

30. Olofsson B, Korpelainen E, Pepper MS, Mandriota SJ, Aase K, Kumar V, et al. Vascular endothelial growth factor B (VEGF-B) binds to VEGF receptor-1 and regulates plasminogen activator activity in endothelial cells. Proc Natl Acad Sci U S A. 1998:95:11709-14.

31. Karakurum M, Shreeniwas R, Chen J, Pinsky D, Yan SD, Anderson M, et al. Hypoxic induction of interleukin-8 gene expression in human endothelial cells. J Clin Invest. 1994;93:1564-70.

32. Shono T, Ono M, Izumi H, Jimi SI, Matsushima K, Okamoto T, et al. Involvement of the transcription factor NF-kappaB in tubular morphogenesis of human microvascular endothelial cells by oxidative stress. Mol Cell Biol. 1996;16:4231-9.

33. Taub DD, Anver M, Oppenheim JJ, Longo DL, Murphy WJ. T lymphocyte recruitment by interleukin-8 (IL-8). IL-8-induced degranulation of neutrophils releases potent chemoattractants for human $T$ lymphocytes both in vitro and in vivo. J Clin Invest. 1996;97:1931-41.

34. Detmers PA, Lo SK, Olsen-Egbert E, Walz A, Baggiolini M, Cohn ZA. Neutrophil-activating protein 1/interleukin 8 stimulates the binding activity of the leukocyte adhesion receptor CD11b/CD18 on human neutrophils. J Exp Med. 1990;171:1155-62.

35. Paccaud JP, Schifferli JA, Baggiolini M. NAP-1/IL-8 induces up-regulation of CR1 receptors in human neutrophil leukocytes. Biochem Biophys Res Commun. 1990;166:187-92.

36. Williamson TH, Baxter GM. Central retinal vein occlusion, an investigation by color Doppler imaging. Blood velocity characteristics and prediction of iris neovascularization. Ophthalmology. 1994;101:1362-72.

37. Noma H, Mimura T, Tatsugawa M, Shimada K. Aqueous flare and inflammatory factors in macular edema with central retinal vein occlusion: a case series. BMC Ophthalmol. 2013;13:78.

38. Hayreh SS, Rojas P, Podhajsky P, Montague P, Woolson RF. Ocular neovascularization with retinal vascular occlusion-III. Incidence of ocular neovascularization with retinal vein occlusion. Ophthalmology. 1983;90: 488-506.

\section{Publisher's Note}

Springer Nature remains neutral with regard to jurisdictional claims in published maps and institutional affiliations.
Ready to submit your research? Choose BMC and benefit from:

- fast, convenient online submission

- thorough peer review by experienced researchers in your field

- rapid publication on acceptance

- support for research data, including large and complex data types

- gold Open Access which fosters wider collaboration and increased citations

- maximum visibility for your research: over $100 \mathrm{M}$ website views per year

At BMC, research is always in progress.

Learn more biomedcentral.com/submissions 